\title{
Unscrambling the evidence for breakfast
}

\author{
Tom Moberly UK editor
}

The BMJ

The first thing Winnie-the-Pooh asks himself every morning is "What's for breakfast?" When Piglet says that he starts the day by wondering, "What's going to happen exciting today," Pooh nods thoughtfully and replies, "It's the same thing."

I'm of much the same mind, and I should declare that as an interest right now. I love breakfast, and I eat it every day without fail. I'm certainly not alone in this, and many people argue that breakfast is not only exciting but good for us. In fact, some official guidelines recommend eating breakfast as a way to lose weight or prevent excess weight gain.

And yet over the past 30 years randomised controlled trials failed to find evidence to support this idea. Most of the data in support of breakfast come from observational studies, and their results are likely to be affected by differences between those who eat and skip breakfast, not least that those who eat breakfast are generally better off and healthier.

This week The BMJ publishes a meta-analysis that seeks to bring together the available evidence (doi:10.1136/bmj.142). Katherine Sievert and colleagues find that people who usually eat breakfast consume on average $260 \mathrm{kcal}$ a day more than those who skip breakfast and weigh on average $0.44 \mathrm{~kg}$ more. In other words, they find no evidence that breakfast helps with weight loss, and their results indicate that it might even lead to weight gain.

The researchers say that their findings should be treated with caution, as the quality of the studies in the meta-analysis is low: all 13 studies they included were at a high or unclear risk of bias.

In the linked BMJ Opinion the epidemiologist Tim Spector laments the flaws in the evidence around nutrition and our approach to generating advice from this evidence (https://blogs. bmj.com/bmj/2019/01/30/tim-spector-breakfast-the-mostimportant-meal-of-the-day). "Prescriptive slow moving dietary guidelines filled with erroneous information look increasingly counterproductive and detract from important health messages," he says.

The lack of high quality evidence in this area is embarrassing, especially when dieting is a multibillion pound industry, when meta-analyses of weight loss drugs include dozens of trials, and when so many guidelines recommend eating breakfast as a way to lose weight.

It may be that, on the issue of whether eating breakfast is a good idea, there is no one answer for everyone. But we should really know whether that is the case. 